\title{
PROPOSAL FOR LOADING TESTS OF BRIDGES - SIMULATION AND LABORATORY EXPERIMENTS
}

\author{
J. Bayer* ${ }^{*}$ S. Urushadze ${ }^{* *}$, M. Černý ${ }^{* * *}$
}

\begin{abstract}
A new dynamic load testing of bridges is proposed and theoretically investigated. A transient analysis of passing vehicle over a bridge in ANSYS and an analytical program in MATLAB for the transient solution of piecewise linear mechanical structures were developed to assess the effects of the proposed dynamic load on a bridge model. According to the first laboratory experiments, it seems that the proposed travelling impulse load could surpass some of the shortcomings and limitations of the currently applied methods of bridge testing. The investigation is a part of a project aimed at drive-by identification of dynamic properties of bridges and further experimental and analytical research will follow.
\end{abstract}

Keywords: dynamic loading tests, transient analysis, vibrations, vehicle-bridge interaction

\section{Introduction}

Dynamic tests of bridges are used either to determine the dynamic increment from traffic loads or to assess the dynamic properties that are used for calibration of analytical models, quality checks and health monitoring (Rücker, 2006). The dynamic properties are usually obtained from modal testing using ambient or deterministic excitation with their advantages and limitations.

Identification of the dynamic properties of bridges and damage detection is a current topic of research in many institutions (e.g. O’Brien, 2017). The damage diagnosis as a successive step can apply also many ways how to reveal the possible damage reaching from directly measured time series, identified natural frequencies (Kashangaki, 1991) and mode shapes (Padney, 1995; overview by Salgado, 2008) over the response functions (Sampaio, 2003) or power spectral densities ( $\mathrm{Li}, 2015)$, of course also under consideration of various statistical methods (Faber, 2000; Mainini, 2017).

A green contemporary branch of this research is the drive-by diagnosis of bridges (Yang, 2004, 2005, 2014). However, the available time for a precise analysis of experiments during vehicle passage is a limiting factor at higher vehicle speeds and the intensity of vibrations induced by the driving vehicle is a limiting factor at lower speeds due to the environmental noise (or other sources of vibrations). Another limiting factor is said to be also the surface roughness (O’Brien, 2017). Therefore, a solution of dynamic excitation was sought that provides us with a higher intensity of dynamic load also at lower speeds of the passing loading-testing vehicle, and possibly not sensitive to the surface roughness.

Dynamic loading tests in the Czech Republic have a long tradition. The use of a standard obstacle (plank) for the evaluation of dynamic increment is a common practice in the Czech Republic for experimental evaluation of the dynamic increment of bridges (ČSN 736209, 1996). The dynamic increment while testing with the obstacle is regularly higher than without it (Cantieni, 1984) and would have

Ing. Jan Bayer, CSc.: Institute of Theoretical and Applied Mechanics of the Czech Academy of Sciences, Prosecká 809/76, 19000 Prague 9, Czech Republic, bayer@itam.cas.cz

** Ing. Shota Urushadze, Ph.D.: Institute of Theoretical and Applied Mechanics of the Czech Academy of Sciences, Prosecká 809/76, 19000 Prague 9, Czech Republic, urushadze@itam.cas.cz

*** Ing. Miloš Černý.: Institute of Theoretical and Applied Mechanics of the Czech Academy of Sciences, Prosecká 809/76, 190 00 Prague 9, Czech Republic, cerny@itam.cas.cz 
approximately the same magnitude as a single impulse from something between the hexa- and heptagonal wheel of a truck.

The final goal is an attempt to combine the above-mentioned approaches to damage diagnosis from a deterministic driving impulse load. As a first stage, however, the necessary analytical tools and experimental equipment have to be prepared (before starting the process of verification and assessment), which is the main topic of the present contribution.

\section{Analysis}

It should be noted that, in this article, the passage of a vehicle is considered as a problem of a moving mass, which is a nonlinear problem in contrast to a moving load which can be considered as a linear problem (Frýba, 1992).

Two procedures were applied to analyse the passage of a mechanical system across the bridge.

The first uses the nonlinear transient analysis of the program ANSYS. A macro in APDL language was written using the shell181, mass21, targe 170 , conta175 and combin14 finite elements with the time step of $0.002 \mathrm{sec}$. The time-space discretization has to be managed carefully because any sudden move (or jump) from the vehicle from one place to another may cause unrealistic effects in the response. The contact elements may also be a source of unrealistic vibrations.

The second one transports the computed natural modes from ANSYS into Matlab and an instantaneous solution in frequency domain using modal superposition method is applied to solve the forced vibrations. Here the model with viscous proportional damping was applied that has the advantage that it operates completely in the real domain. The degrees of freedom (DOFs) are transferred from the driving path only, not the complete set of DOFs of the model which can lead to inaccuracy; however, it has lower CPU requirements than the ANSYS solution.

If the load is discontinuous, e.g. the travelling impulse modelled as the Dirac Function, there is a good agreement between the two mentioned analytical approaches (see Fig. 1).

To achieve a confidence with the analysis it is necessary to calibrate the analytical model with experiments.

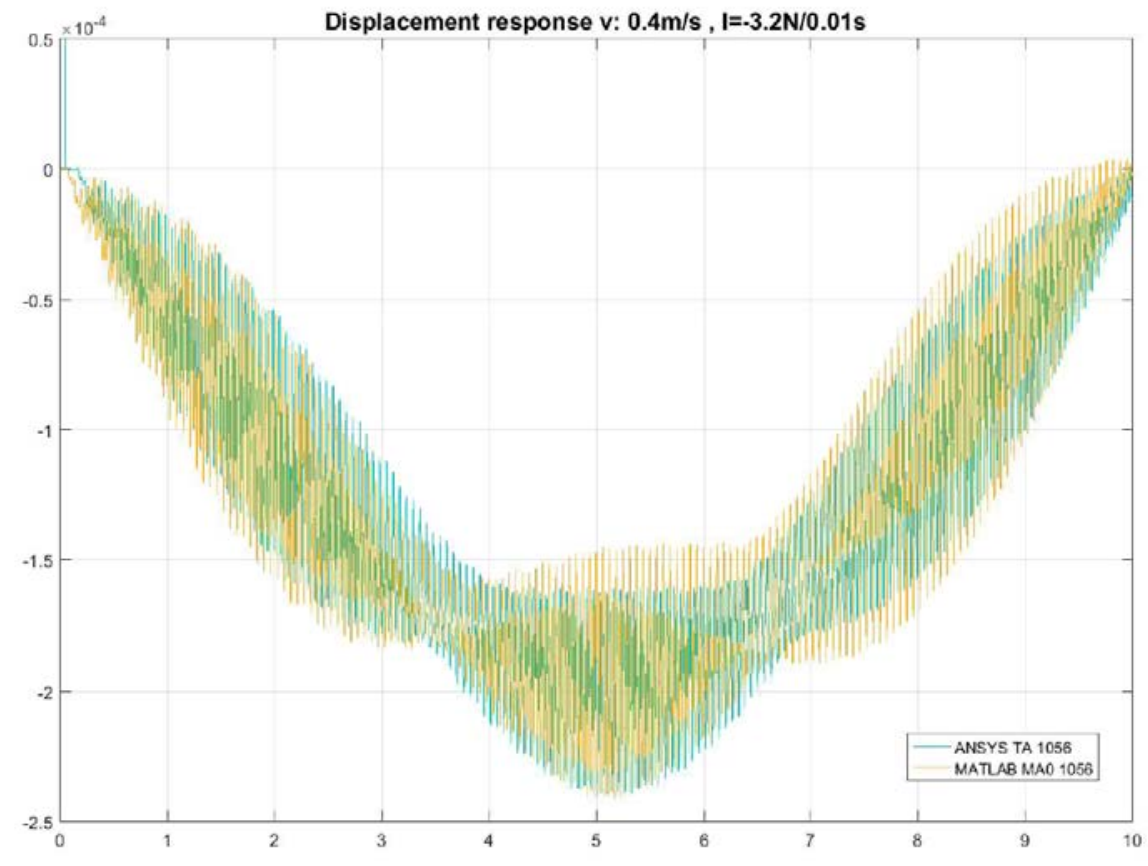

Figure 1: Response of the midpoint of the bridge to moving impulse load 


\section{Experiments}

The experimental programme has more successive stages. The experimental modal analysis has to be carried out at first to determine the most important parameters for the analysis such as the natural frequencies and the damping. Then the passage of the mass and the passage of the mass on the octagonal wheel followed until now. The mass of the vehicle was $0.72 \mathrm{~kg}$ and the mass of the $4 \mathrm{~m}$ long simple supported bridge model of acrylic glass was about $23 \mathrm{~kg}$ with the first natural frequency of $3 \mathrm{~Hz}$. The vehicle equipped with octagonal wheels passing over the bridge model can be seen in Figure 2.

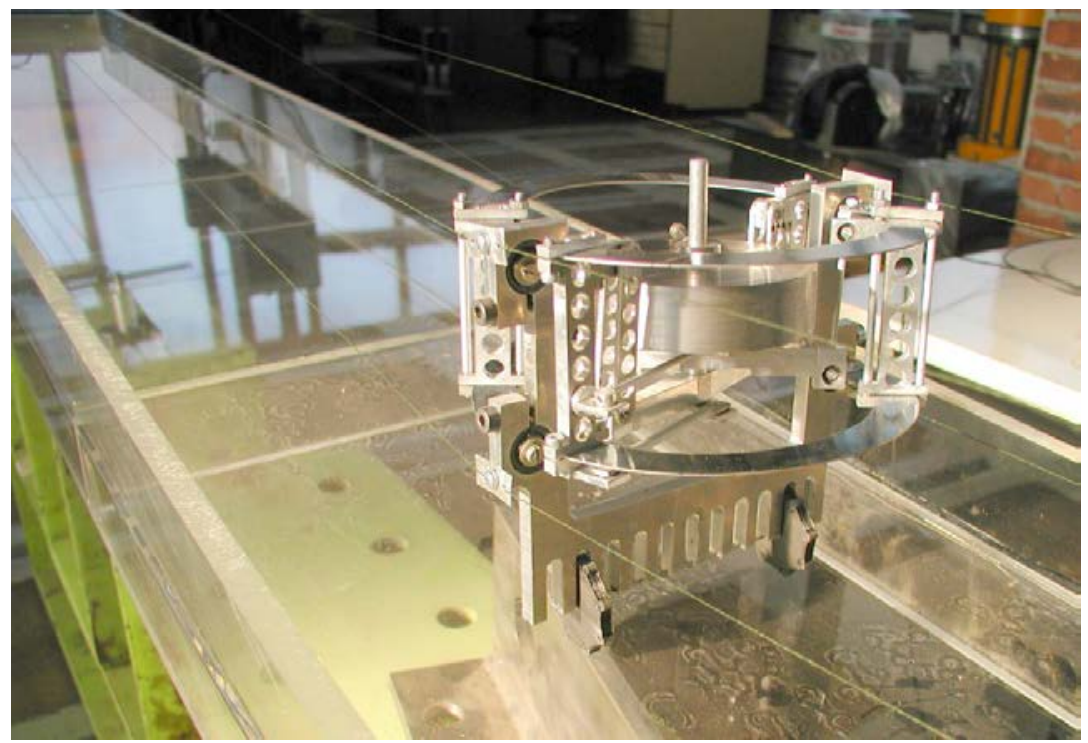

Figure 2: Testing vehicle passing on octagonal wheels over the bridge model

Modelling of the loading function of an octagonal tyre is not a simple task. Apart from of the moving mass there is the constantly changing situation when the tyre is supported on two or on one point causing a pulsating load whose intensity and form depends on the deformation properties of the applied material. Here, we considered the experiment as a necessary complement to the analysis.

The experiments confirmed that the effect of the cogwheel distinctly amplifies the response of the bridge even at low frequencies and slow velocity of the vehicle (see Fig. 3). The difference in the magnitude of the bridge response between the cogwheel and plain wheel excitations diminishes with higher speeds. But as was already mentioned in the introduction, the low speeds of the vehicle are of interest because of longer times for the analysis of the vibrations during the passage of the vehicle, which is favourable from the health monitoring point of view. Although the intensity of the cogwheel load is greater than the intensity of the traditional tyre it may not be always sufficient because of the environmental vibration noise present on real structures. Therefore, tests in situ will be also necessary.

At higher speeds transient effects could be observed and will be the subject of further investigations.

\section{Conclusions}

Using a moving mass on cogwheels as a source of dynamic excitation is a promising method for the testing of bridges. A vehicle equipped with cogwheels can provide a distinctly higher dynamic load at slow vehicle speed keeping the advantage that the load is moving continuously along the bridge, thus giving much better conditions for the experimental analysis from the health monitoring point of view. This type of excitation simply surpasses the obstacles that may cause the surface roughness when using vehicles for bridge excitations.

The analytical and experimental tools necessary were developed and prepared to continue the research.

\section{Acknowledgement}

Sponsorship by the grant GAČR 17-26353J is very much appreciated. 


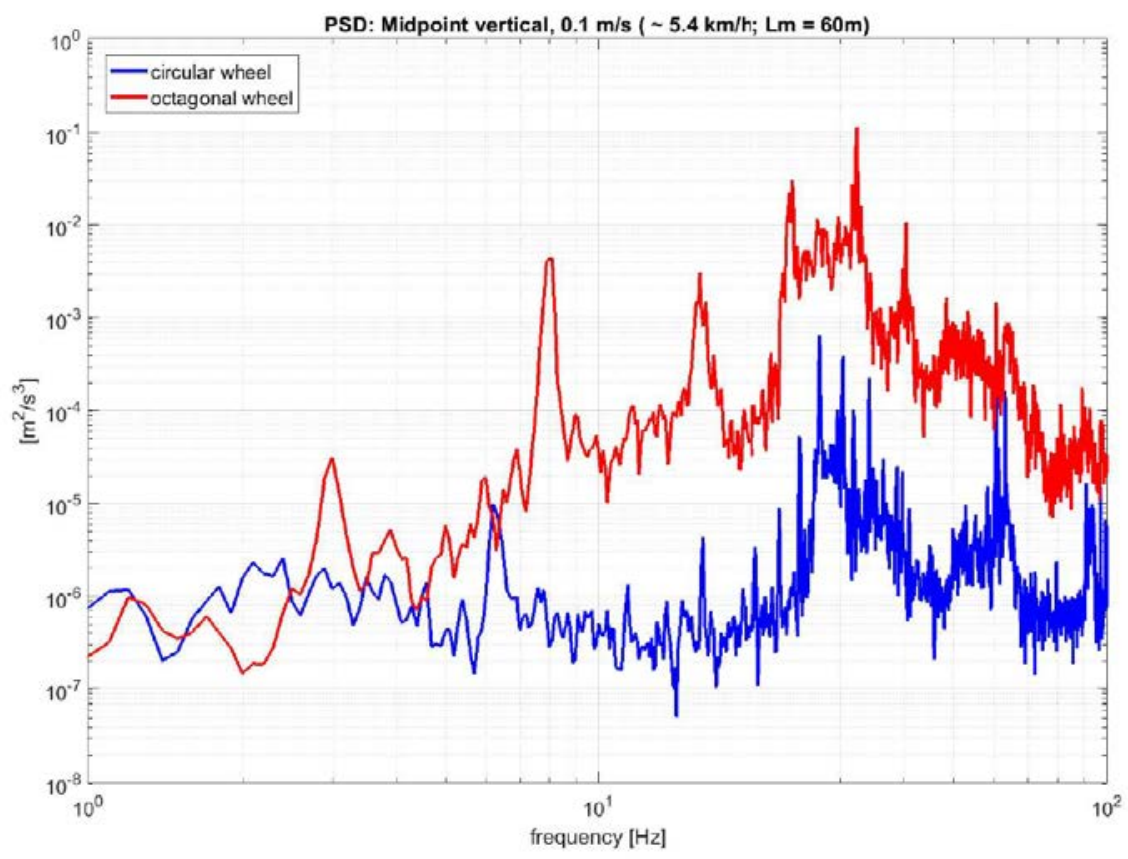

Figure 3: Average acceleration PSD from the midpoint of the bridge model using two types of wheels

\section{References}

Cantieni R. C. (1984) Dynamic Load Testing of Highway Bridges, IABSE Proc. 3/1984, ISSN-0377-7278

ČSN 736209 (1996), Zatěžovací zkoušky mostů, Czech National Standard

Faber M.H., Val D.V., Stewart M.G., (2000) Proof load testing for bridge assessment and upgrading, Engineering Structures 22, pp. 1677-1689

Frýba L. (1992) Dynamics of Railway Bridges, Academia Praha, 2nd edition 1996, ISBN 0-7277-2044-9, 80-2000544-7.

Kashangaki, Thomas A. L. (1991) On-orbit damage detection and heath monitoring of large space trusses - status and critical issues. NASA Tech. Memorandum 104045, https://ntrs.nasa.gov/archive/nasa/ casi.ntrs.nasa.gov/19910012266.pdf

Li J., Hao H., Xia Y. Zhu H-P. (2015) Damage assessment of shear connectors with vibration measurements and power spectral density transmissibility. Structural Engineering and Mechanics, Vol. 54, No. 2, 257-289, DOI: http://dx.doi.org/10.12989/sem.2015.54.2.257

Mainini L., Willcox K.E. (2017) Data to decisions: Real-time structural assessment from sparse measurements affected by uncertainty, Computers and Structures 182, pp. 296-312

O’Brien E.J., Martinez D., Malekjafarian E.S. (2017) Damage detection using curvatures obtained from vehicle measurements, J Civil Struct Health Monit, 2017/7:333-341 DOI: 10.1007/s13349-017-0233-8

Pandey, A. K., Biswas, M. (1995) "Experimental Verification of Flexibility Difference Method for Locating Damage in Structures". Journal of Sound and Vibration, 184(2), pp. 311-328. https://doi.org/10.1006/jsvi.1995.0319

Rücker W., Hille F. Rohrmann R. (2006) Guideline for Structural Health Monitoring, BAM, SAMCO - F08b, Berlin

Salgado, R. (2008) "Damage Detection Methods in Bridges through Vibration Monitoring: Evaluation and Application”. Thesis ISISE-University of Minho, http://repositorium.sdum.uminho.pt/handle/1822/9023

Sampaio R. P. C., Maia N. M. M., Silva J. M. M., Almas E. A. M. (2003) Damage Detection in Structures: From Mode Shape to Frequency Response Function Methods, Mechanical Systems and Signal Processing 17(3), 489498, DOI: $10.1006 / \mathrm{mssp} .2002 .1506$

Yang Y. B., Li Y. C., Chang K. C. (2014) Constructing the mode shapes of a bridge from a passing vehicle: a theoretical study, Smart Structures and Systems, 13, No.5: pp. 797-819, http://hdl.handle.net/10197/7135, http://dx.doi.org/10.12989/sss.2014.13.5.775

Yang Y. B, Lin C, Yau J. (2004) Extracting bridge frequencies from the dynamic response of a passing vehicle. J Sound Vib, 272(3): pp. 471-493

Yang Y. B., Lin C. W. (2005) Vehicle-bridge interaction dynamics and potential applications, Journal of Sound and Vibration 284, pp. 205-226 